\title{
The effect of mercuric chloride treatment as biocide for herbaria on the indoor air quality
}

\author{
John Havermans ${ }^{1 *}$, René Dekker ${ }^{2}$ and Ron Sportel ${ }^{3}$
}

\begin{abstract}
One of the most previous conservation treatments for plant specimen in herbarium collections was mercuric chloride $\left(\mathrm{HgCl}_{2}\right)$. However, due time $\mathrm{HgCl}_{2}$ may decompose and it may cause (metallic) mercury $(\mathrm{Hg})$ emission. $\mathrm{Hg}$ vapour in indoor air should be avoided as mercury poisoning can already occur at levels of $6 \mu \mathrm{g} / \mathrm{m}^{3}$. Both field and laboratory studies were carried out while the $\mathrm{Hg}$ concentration was analysed in the air. Field studied included analysis of the indoor air in the repository and analysis of the concentration inside a herbarium box. Subsequently lab experiments were carried out on measuring the Hg emission using a small scale emission chamber. The lab studies proved that the emission of $\mathrm{Hg}$ from collections is according to the theories of Hoetjer-Berger-Fuji and therefore it can be seen as a continuous emission. Field studies concluded that workers and visitors may be subjected to a high mercury concentration in the repositories. Opening a herbarium box may even cause a peak concentration of over $80 \mu \mathrm{g} / \mathrm{m}^{3}$. The highest concentration observed in the repositories was $13 \mu \mathrm{g} / \mathrm{m}^{3}$. Although this value is lower than the official Dutch threshold levels of $20 \mathrm{\mu g} / \mathrm{m}^{3}$ (time weight average over $8 \mathrm{~h}$ for work places), this concentration has to be considered as high. Based on the lab studies, it can be concluded that by adjusting the ventilation rate in work rooms and repositories, the mercury concentration indoor can be lowered drastically and improve the indoor air quality. However care should to be taken when opening herbarium boxes, due to possible high mercury emission.
\end{abstract}

Keywords: Herbarium, Mercury emission, Indoor air quality, Occupational health

\section{Background}

\section{Mercuric chloride and conservation}

One of the most used biocides for disinfection of natural history collections and in special herbarium collections is mercuric chloride (or mercury(II)chloride, $\mathrm{HgCl}_{2}$, CAS number 7487-94-7). $\mathrm{HgCl}_{2}$ forms solid white crystals, and once it was applied as a medicine against e.g. syphilis. However, $\mathrm{HgCl}_{2}$ is extremely poisoning and has the ability to sublimate. $\mathrm{HgCl}_{2}$ decomposes into metallic mercury $\left(\mathrm{Hg}^{\mathrm{O}}\right.$, or just $\left.\mathrm{Hg}\right)$ by reduction. $\mathrm{Hg}$ is the only metal that is a liquid at room temperature and due its sublimation a high concentration of $\mathrm{Hg}$ vapour in the air may easily occur [1].

\footnotetext{
*Correspondence: john.havermans@tno.nl

${ }^{1}$ TNO Applied Environmental Chemistry, Utrecht, The Netherlands Full list of author information is available at the end of the article
}

Both $\mathrm{HgCl}_{2}$ and $\mathrm{Hg}$ (vapour) are extremely dangerous for our health, as for example $\mathrm{Hg}$ taken up by the lungs will accumulate in the kidney and brains [2]. The World Health Organisation, WHO, is classifying $\mathrm{Hg}$ as 'extremely hazardous class 1a' [1, 3]. In the European Union the advisory value for health of $\mathrm{Hg}$ in the indoor air is set to $50 \mathrm{ng} / \mathrm{m}^{3}$ (average annual concentration) and therefore it is lower than the official Dutch threshold level of $20 \mu \mathrm{g} / \mathrm{m}^{3}$ (time weight average over $8 \mathrm{~h}$ ) [4].

Up to 1980 , herbarium collections were disinfected by means of the use of mercuric chloride [5] and, for example, in the Netherlands it was last used in 1984 [6]. Based on surveys it has become clear that different methods were applied [7], for example by soaking or brushing materials using a solution of $\mathrm{HgCl}_{2}$ with ethanol. Herbarium samples can continue to emit metallic mercury many decades after their last treatment with mercuric chloride $[5,8-11]$.

\section{Chemistry Central}

(c) 2015 Havermans et al. This article is distributed under the terms of the Creative Commons Attribution 4.0 International License (http://creativecommons.org/licenses/by/4.0/), which permits unrestricted use, distribution, and reproduction in any medium, provided you give appropriate credit to the original author(s) and the source, provide a link to the Creative Commons license, and indicate if changes were made. The Creative Commons Public Domain Dedication waiver (http://creativecommons.org/ publicdomain/zero/1.0/) applies to the data made available in this article, unless otherwise stated. 


\section{Release of mercury}

The emission of mercury $(\mathrm{Hg})$ from herbarium collection forms a serious occupational health hazard, not only for the workers at the collection, but also for the visitors and researchers who need to work with the collection materials. In the Netherlands (National Herbarium collection repositories, now dismounted) steady sate concentrations in the indoor were found to be over $10 \mu \mathrm{g} \mathrm{Hg} / \mathrm{m}^{3}$ while for example other collections were causing concentrations of mercury indoor of about $25 \mu \mathrm{g} \mathrm{Hg} / \mathrm{m}^{3}$ (Cambridge herbarium) and $40 \mu \mathrm{g} \mathrm{Hg} / \mathrm{m}^{3}$ (MAF, Madrid). However, opening collection boxes or cabinets where specimens are stored can cause a peak concentration of $50 \mu \mathrm{g} \mathrm{Hg} / \mathrm{m}^{3}$ and higher [5, 8-11].

Different mechanisms can be hypothesised as responsible for the emission of mercury from herbarium collections. First the ionogenic reactions, uptake of electrons by the mercuric ion, that may occur even at the normal moisture content in cellulose materials [12]:

$$
\begin{aligned}
& \mathrm{Hg}^{2+}+2 e \rightarrow \mathrm{Hg}\left(\mathrm{E}^{0}=0.851 \mathrm{~V}\right) \\
& 2 \mathrm{Hg}^{2+}+2 e \rightarrow \mathrm{Hg}_{2}^{2+}\left(\mathrm{E}^{0}=0.920 \mathrm{~V}\right) \\
& \mathrm{Hg}_{2}^{2+}+2 e \rightarrow 2 \mathrm{Hg}\left(\mathrm{E}^{0}=0.797 \mathrm{~V}\right)
\end{aligned}
$$

Practically there is moisture present during the treatment, and therefore this may cause the initiation of oxidation and reduction reaction in cellulose-containing specimens. These reactions may enhance in case, e.g., more hemi-cellulose is present as these polyoses contain more reactive carbonyl groups $\left(\mathrm{C}_{\mathrm{H}}=\mathrm{O}\right)$ than cellulose $[13,14]$. A carbonyl group may be oxidized resulting in a carboxyl group (-COOH) (Fig. 1).

For example, the oxidation of cellulose produces electrons according to

$$
\begin{aligned}
& \text { Cellulose }-\mathrm{C}_{\mathrm{H}}=\mathrm{O} \\
& \quad \rightarrow \text { Cellulose }-\mathrm{COOH}+2 e \\
& \mathrm{O}_{2}+2 e \rightarrow 2 \mathrm{O}^{-}
\end{aligned}
$$

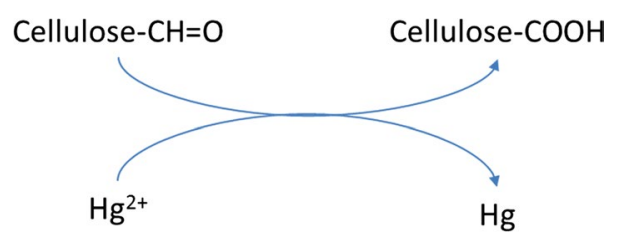

Fig. 1 A suggested pathway on the formation of volatile mercury. The carbonyl group of, e.g., cellulose reacts with mercuric ions to form an organic acid while metallic mercury is formed and can be emitted
Summarized:

$$
\begin{gathered}
\text { Cellulose }-\mathrm{C}_{\mathrm{H}}=\mathrm{O}+1 / 2 \mathrm{O}_{2} \\
\rightarrow \text { Cellulose }-\mathrm{COOH}
\end{gathered}
$$

It was also suggested that the reduction of $\mathrm{Hg}^{2+}$ can occur as a two-step reaction [15]. This is based on the $\mathrm{Hg}^{+}$determination in the specimen and the fact that $\mathrm{Hg}$ is found in the indoor air. Also Purewal demonstrated that, due to the occurring reactions, the mount paper used to display the specimens will shine fluorescent orange under a UV lamp if mercury is present, however it has not be fully proven if the fluorescent is due to the mercury-cellulose complex or due to paper degradation.

The analysis and prediction of the emission of volatiles from materials was firstly reported in European Committee for Standardization (CEN) in 1984, [16]. Other important work discussing the emission of volatiles was published by the European Cooperation in Science and Technology Network platform (COST) by COST action 613 "indoor air Quality and its impact on man" and described in several reports on how to measure the steady state concentration in situ, how to predict the emission and also how to make interpretation of the observed emission results [17-20]. Only in the last decade has the role of the emission for objects of cultural value come under discussion. This not only because of the quality of the material where the cultural artefact has been made of, but more related to the conservation treatment and its impact on occupational health.

It has been proven frequently that there is a relation between the emission rate and the ventilation rate [21, $22]$. Once this relation is found, the concentration of the indoor air can be modelled. The principle of the measurement is as above, however the steady state concentration is measured using at least 3 datapoints (different ventilation rates). The relation between the concentration of a compound and the ventilation rate can be described according to the Hoetjer equation $[21,23]$ and later more known as the Hoetjer-Berge-Fujii equation [24]:

$$
\frac{1}{C}=\frac{1}{C_{e}}+\left(\frac{1}{k x C_{e}}\right) x\left(\frac{n}{L}\right)
$$

Here $\mathrm{C}=$ steady state concentration $\left(\mu \mathrm{g} \mathrm{m}^{-3}\right)$, $\mathrm{C}_{\mathrm{e}}=$ equilibrium concentration at a ventilation rate of 0 $\left(\mathrm{h}^{-1}\right), \mathrm{k}=$ mass transfer coefficient, $\mathrm{n}=$ air exchange rate $\left(\mathrm{h}^{-1}\right), \mathrm{L}=$ loading factor $\left(\mathrm{m}^{2} \mathrm{~m}^{-3}\right)$

\section{Experimental}

\section{Concentration of mercury inside a herbarium box}

As the herbarium materials were subjected to a mercuric chloride it is assumed that the herbarium boxes, having several treated sheets inside, are the main source for the mercury concentration indoor. In order to determine 
the initial concentration of mercury inside a herbarium box the concentration was measured using a Mercury Vapour Monitor MV-3000 from Mercury Instruments (Anonymous 2013). We applied the most simple way, i.e., to put directly the inlet of the mercury monitor inside the box as shown in Fig. 2. As the monitor has an air flow of approx. $0.6 \mathrm{~L} / \mathrm{min}$ reading was done after $30 \mathrm{~s}$ to minimize the amount of outside air entering the box.

\section{Concentration mercury in the repositories}

Repository workers are subjected to the indoor air quality present in the repositories and thus to the present concentration of mercury in the air. For the concentration analyses and measurements of mercury a Mercury Vapour Monitor MV-3000 from Mercury Instruments was used [25]. For the mercury concentration measurements in the repositories, a random walk was carried out and on different locations readings were taken. The walk was from the corridor, where a copy machine is located, to a connecting corridor with two repositories (Fig. 3).

\section{Mercury emission}

For the evaluation of the mercury concentration of the content of a herbarium box at different ventilation

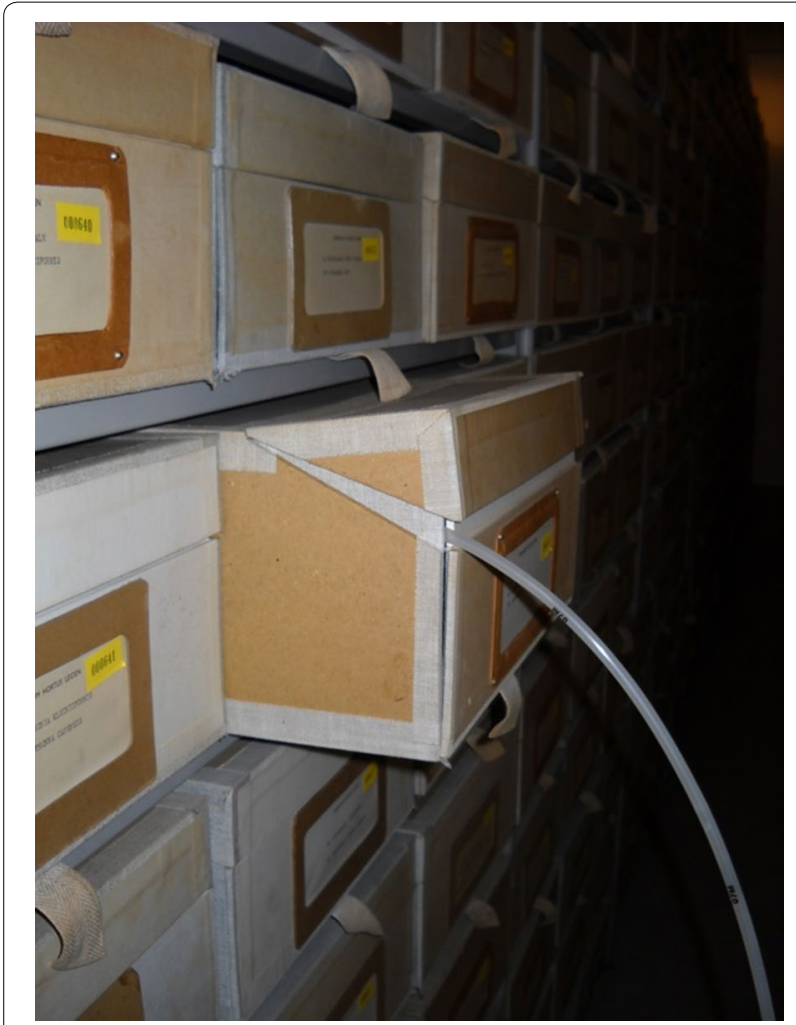

Fig. 2 Field studie on measuring the mercury concentration inside a herbarium box. Example of direct sampling of air rates a small emission chamber was used. The chamber was developed within the EU-PaperTreat project [26]. Within this chamber not only the ventilation rate could be adjusted, but also the circulation rate, comparable to archival storage rooms having a condition of a ventilation rate of $0.21 / \mathrm{h}$ and a recirculation rate of $2.01 / \mathrm{h}$.

The chamber is made of stainless steel and has a volume of $0.1 \mathrm{~m}^{3}$. This size has an advantage that it is simple to reach a high loading (i.e., emitting surface of the material compared to the volume of the chamber). The chamber is connected to an air inlet, provided with a filter to assure non-polluted air and the outlet is connected to two pumps and the mercury monitor. One of the pumps is responsible for bringing the air back to create the circulation rate. The ventilation rate is created by the sum of the flows of one pump plus the analysers.

Figure 4 shows the experimental set up including how the materials are placed inside the chamber. For our research we used a circulation rate of $2.01 / \mathrm{h}$ and three ventilation rates: $1,1.5$ and $21 / \mathrm{h}$.

\section{Results and discussion}

Figure 5 shows a frequency distribution of the concentrations measured using 29 randomly selected herbarium boxes. Based on this graph it is suggested that the concentration of mercury inside a herbarium box will be mainly between 10 and $40 \mu \mathrm{g} / \mathrm{m}^{3}$, while concentrations of higher than $80 \mu \mathrm{g} / \mathrm{m}^{3}$ are possible. Therefore opening a herbarium box should be done with care and preferable precaution should be taken to avoid inhalation of high concentration of mercury.

The fact that there is a concentration of mercury inside a herbarium box indicates that mercury should also emit from the boxes into the storage rooms. And this is indeed what we observed in the building that was housing the collection. This building housing the collection had two floors and both floors were housing parts of the collection. Both floors are separated by means of doors that are closed in a normal situation. The repositories have also doors that should be closed in normal situations, however during the days we were measuring all doors were open. The ground floor is in direct open connection with the outdoors, via the main entrance and side entrances. The first floor can be entered by a corridor and stair with closed doors on the ground and first floor. Entering the first floor of the building, near the copy machine, we observed between 6.1 and $6.7 \mu \mathrm{g}$ mercury per $\mathrm{m}^{3}$. Walking through the corridor we observed 6.5-8.5 $\mu \mathrm{g}$ mercury per $\mathrm{m}^{3}$ and finally inside the repository we observed 10-13 $\mu$ g mercury per $\mathrm{m}^{3}$ indeed indicating that mercury emits from the collection boxed to the indoor air of the building. The rooms where administrative and research 


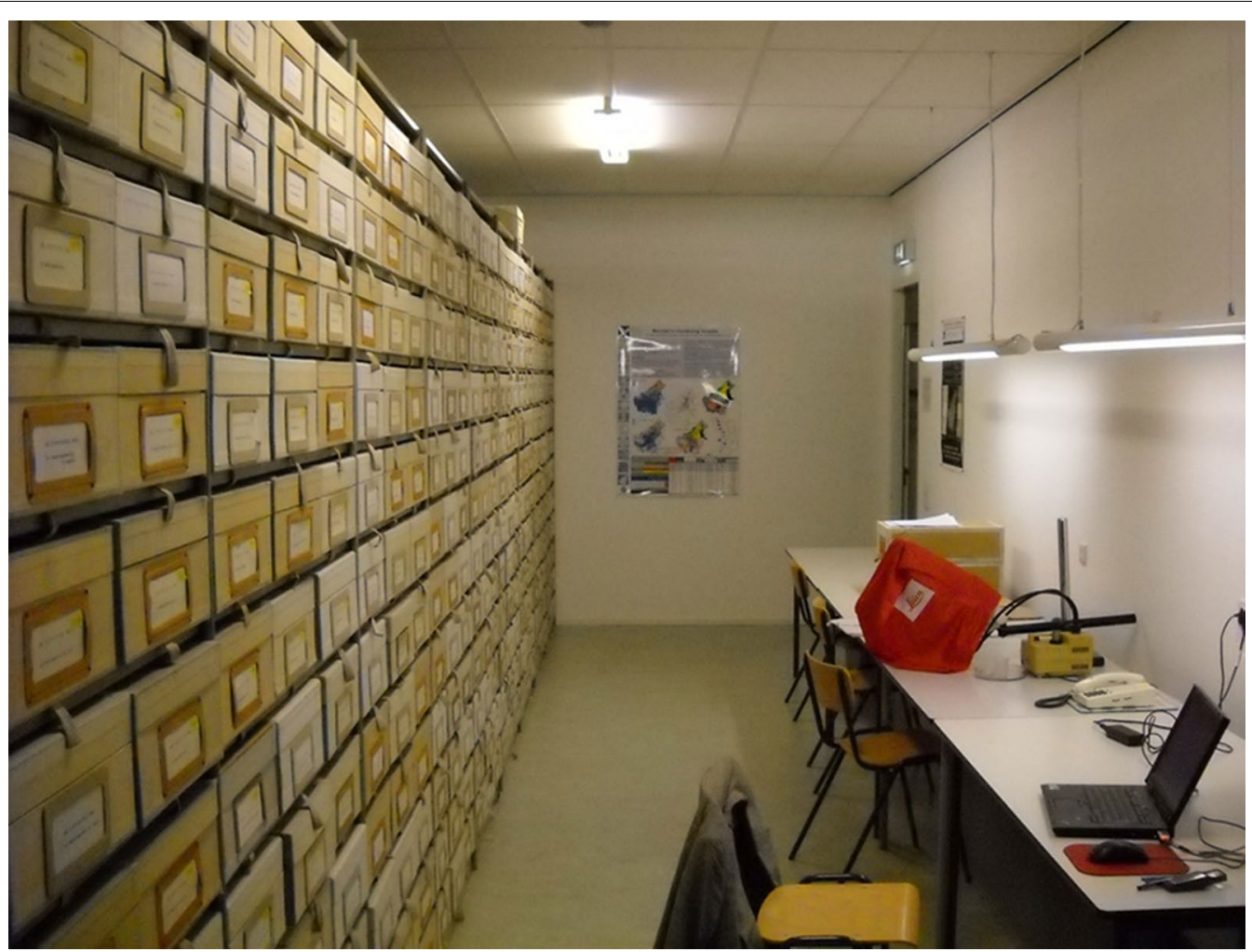

Fig. 3 Entrance of one of the repositories. Here work places are present for external visitors
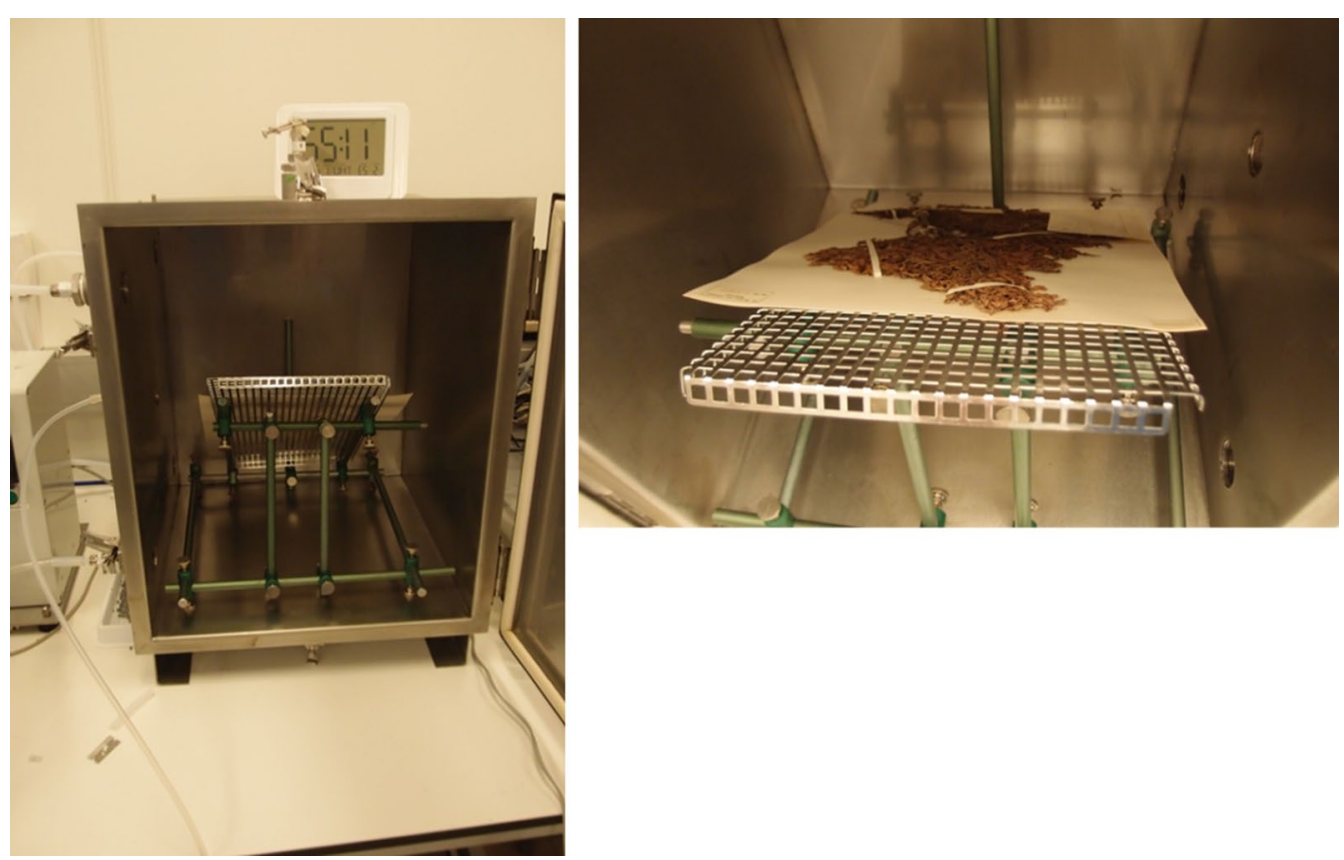

Fig. 4 The experimental set up for the mercury emission measurements. Left the stainless steel chamber, right an example on how specimen can be placed in the chamber 


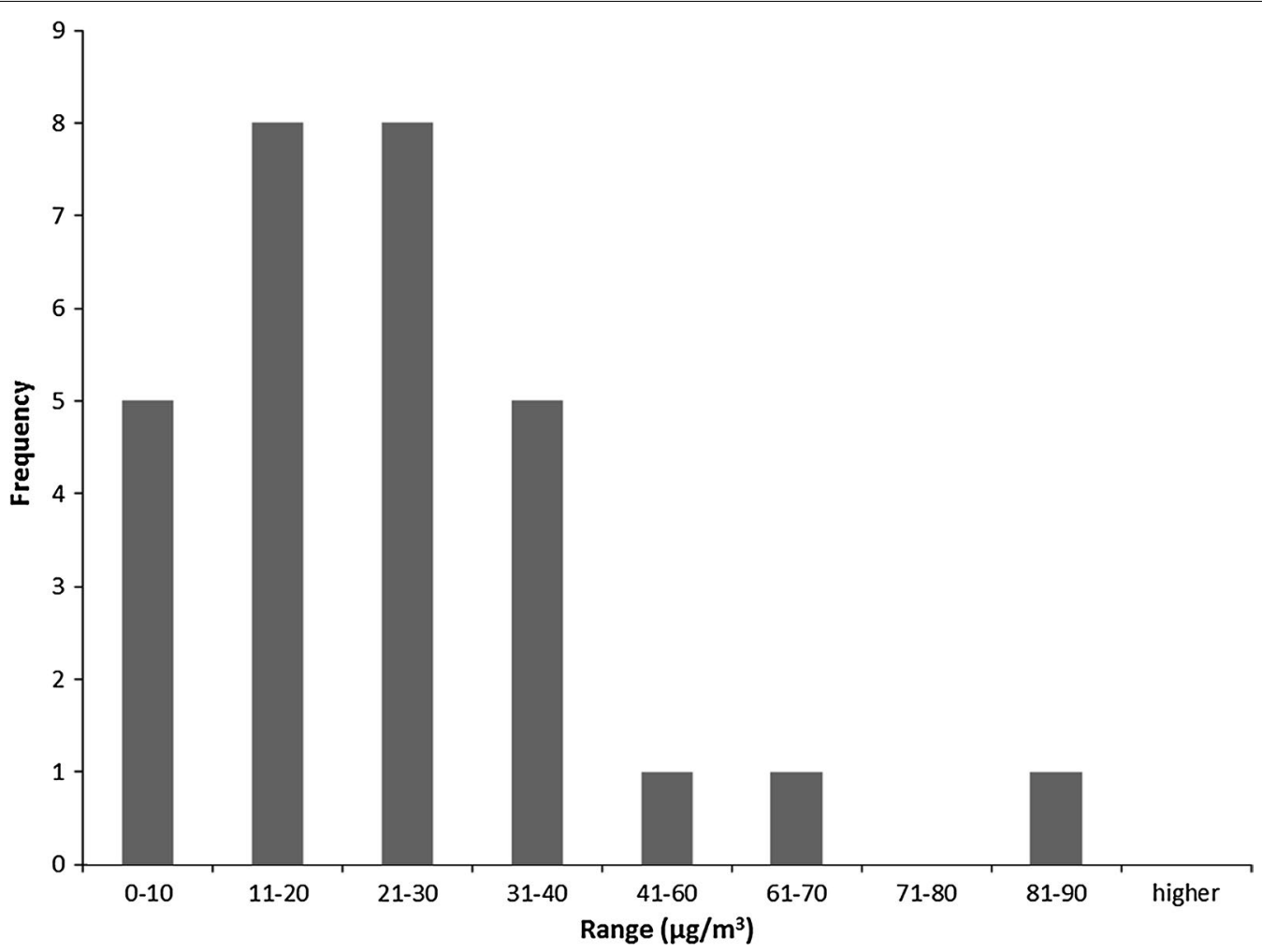

Fig. 5 Distribution of the mercury concentration inside a herbarium box, measured directly inside the box using a Mercury Vapour Monitor MV-3000

work is being carried out were all connected by a door directly with the corridor. In these rooms we observed concentrations of mercury varying from $2 \mu \mathrm{g} / \mathrm{m}^{3}$, where the door of the room was closed, up to $8.5 \mu \mathrm{g} / \mathrm{m}^{3}$ where doors were open.

Although it looks obvious, that the mercury concentration in the working areas comes from the repositories, we checked the flows of air by means of smoke-tubes. The generated smoke could be easily followed and showed the stream of air was from the repositories towards the corridor and subsequently the working rooms.

Although the found concentrations are below the official Dutch threshold levels of $20 \mu \mathrm{g} / \mathrm{m}^{3}$ (time weight average over $8 \mathrm{~h}$ for work places) they have to be considered as high as it is known that serious mercury poisoning can already occur at levels of $6 \mu \mathrm{g} / \mathrm{m}^{3}$, especially for young workers and women who are pregnant [27]. Finally looking at the advisory maximum concentration given by Boerstra et al. of mercury in living houses, i.e., $0.05 \mu \mathrm{g} /$ $\mathrm{m}^{3}$, it has to be concluded that the found values can be seen as high.

Based on this work, serious actions were undertaken by the 'herbarium', for example, closing doors where the doors should be closed and improving the quality of the ventilation. By improving the ventilation, thus the amount of fresh air led into the building increased, may result in diluting the mercury concentration. This was also demonstrated by the experiments on the effect of the ventilation rate on the mercury emission.

Figure 6 shows an example of the results on the emission of mercury from a content of a herbarium box in relation to the ventilation rate. Here the ratio of $\mathrm{n} / \mathrm{L}$ in $\mathrm{m} / \mathrm{h}$ (ventilation rate divided by the loading) is expressed on the $\mathrm{x}$-axis while the reciprocal concentration in $\mathrm{m}^{3} / \mu \mathrm{g}$ has been placed on the $y$-axis. The bundle tested consists of 41 folders filled with total 87 sheets of herbarium specimens. All calculated concentrations were corrected for a blank, i.e., concentration of mercury in the sampled air when no specimens were present in the emission chamber. The measured point at $\mathrm{n} / \mathrm{L}=0 \mathrm{~m} / \mathrm{h}$ has been taken by connecting the outlet of outgoing air with the inlet of the incoming air of the emission chamber.

As can be seen from Fig. 6, the emission of mercury follows very well the theories of Hoetjer. Based on the results of this experiment it is suggested that the emission from mercury is according to a continuous emission process, i.e., the emission of mercury from the specimen will be due to the presence of relatively high concentration of bound mercury on the specimen. Purewal [15] already suggested that it is due to the 


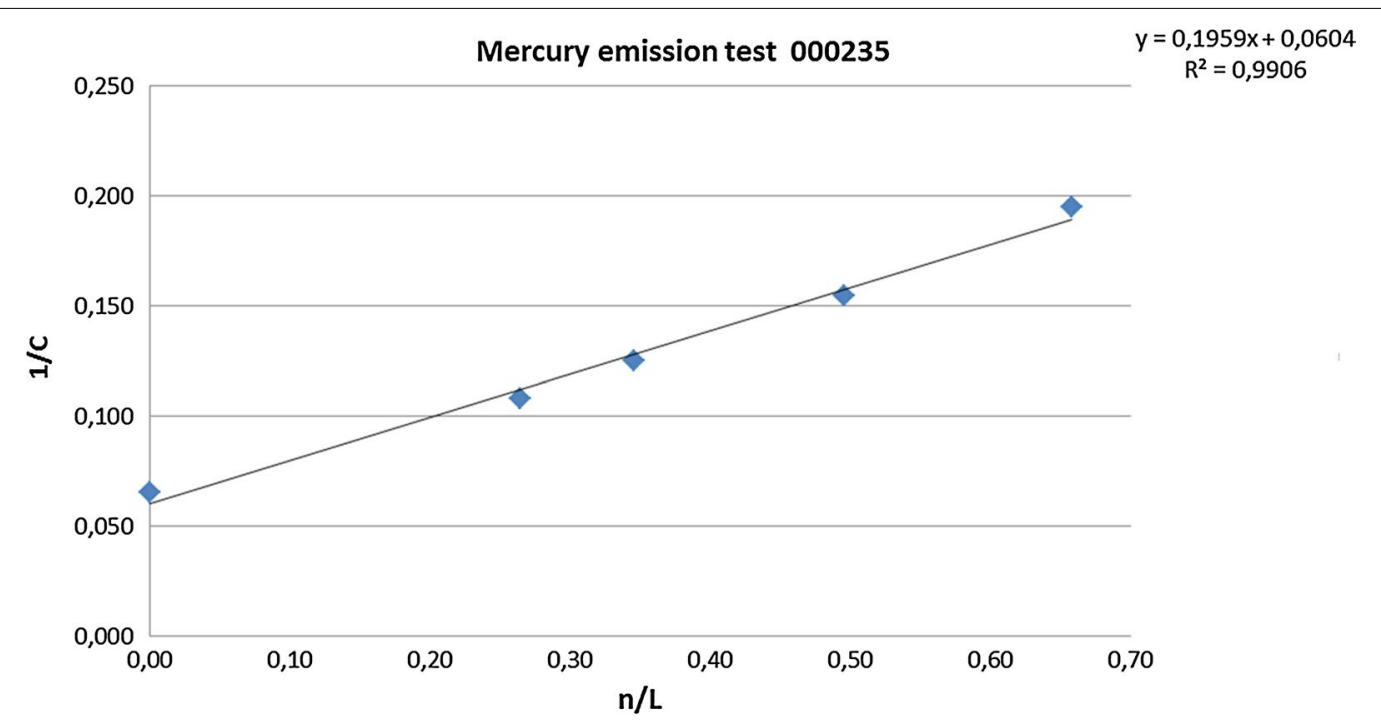

Fig. 6 Calculated emission line of mercury from a herbarium materials

uptake of mercury by the mount paper, however based on our work we suggest that it is mainly due to the presence of paper deterioration products, because mercuric chloride was found as particles on the specimen (Fig. 8). Some fallen leaves from the tested materials were put under a scanning electron microscope coupled with energy dispersive X-ray spectroscopy (SEM/EDX). In this example white spots on the leaf could be clearly observed by means of a backscattered electrons detector. The EDX analysis indicated the presence of both mercury and chloride, which suggests that the mercury is combined with chloride (Fig. 7).

The fact that Purewal [15] found a fluorescence effect may indicate that this is not only due to presence of mercury but also due to occurring reactions, for example the Fenton reaction of cellulose caused by the presence of transition metals as mercury(I)- and (II)-ions. The degradation of the cellulose may result in discoloration as it is found on the flyers present between the specimens (see Fig. 8).

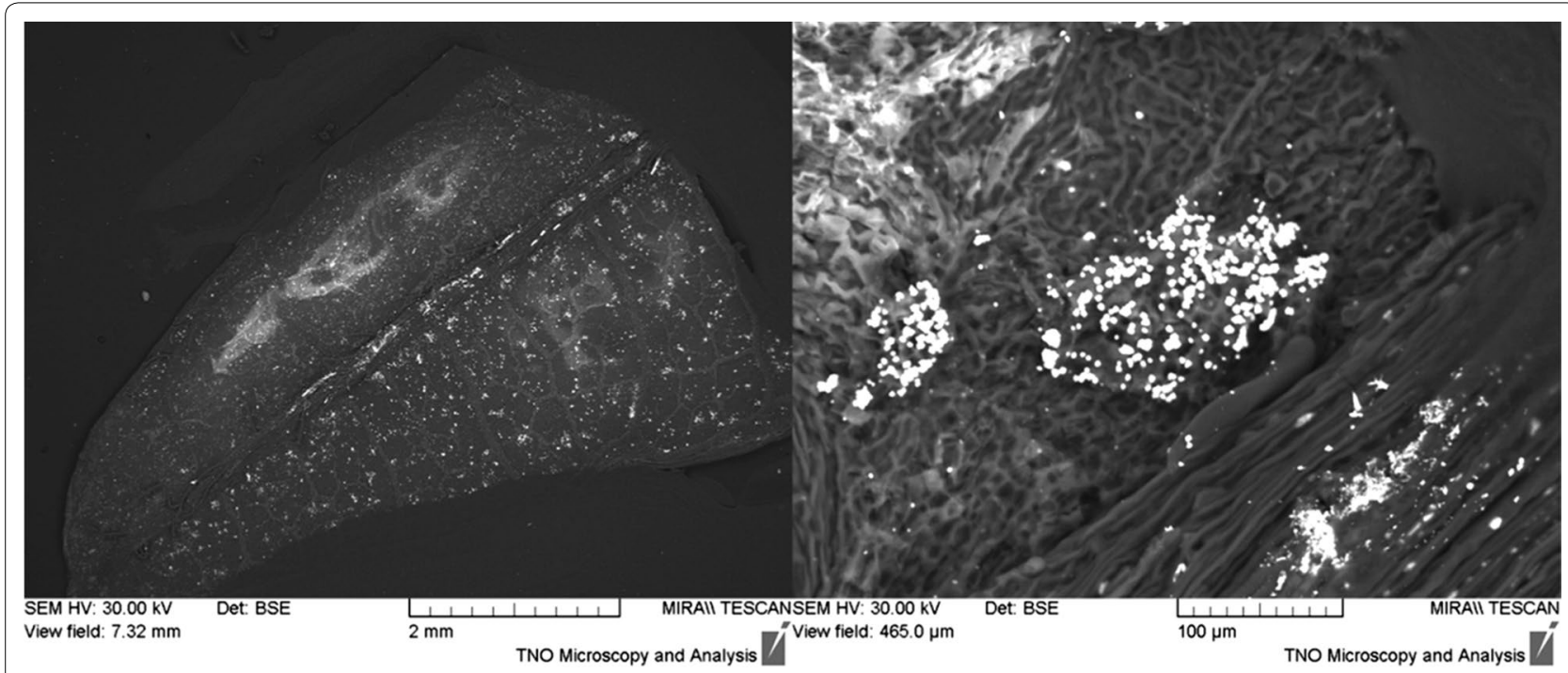

Fig. 7 SEM/EDS recordings of a part of a leaf, from the collection used for the emission test. White spots were indicated as mercury and chloride containing crystals 


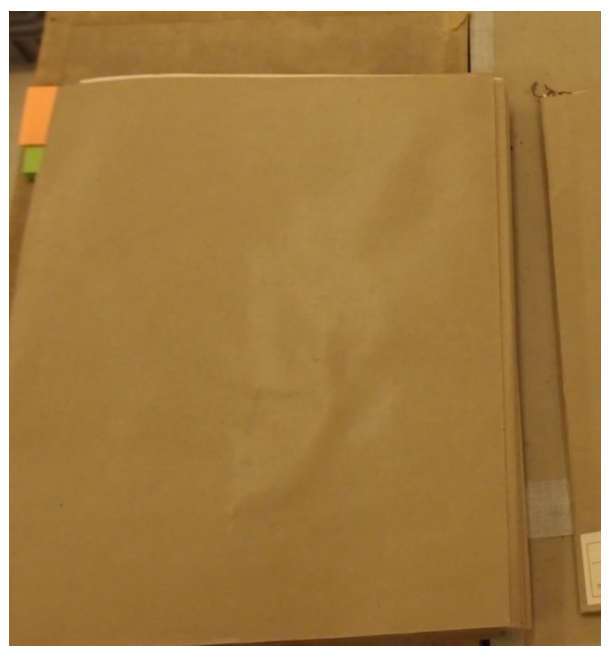

Fig. 8 A fly leaf that was placed on the specimen showing serious discoloration exactly on the location where mercury chloride treated objects were placed

\section{Conclusions}

Based on our work, we conclude that herbarium collections, treated with mercuric chloride (sublimate process) may cause serious emission of (metallic) mercury and thus contaminating the indoor air of, e.g., the repositories.

The collection may emit mercury to its environment and may contaminate not only the repositories but also the neighbouring working rooms. Although we found concentration of mercury indoors varying from $2 \mu \mathrm{g} / \mathrm{m}^{3}$ on locations where fresh air could be entered easily to $13 \mu \mathrm{g} / \mathrm{m}^{3}$ in the repositories, these concentrations should be lowered even though they are below the current Dutch threshold levels for work areas $\left(20 \mu \mathrm{g} / \mathrm{m}^{3}\right)$. Even at $6 \mu \mathrm{g}$ / $\mathrm{m}^{3}$ mercury may cause mercury poisoning.

Inside a herbarium box the concentration of mercury may even exceed the threshold level and therefore opening a box may affect the occupational health if no precautions are taken. Precautions for personnel to take, such as, wearing gloves, the use of ventilating cabinets, keeping head away from the boxes immediately after opening, or others are therefore recommended.

To lower the mercury concentration in, e.g., the repositories or reading rooms, the ventilation rate should be adjusted. For this purpose a simulation calculation based on several emission measurements of collection sheets may be helpful as the mercury emission from the content of a herbarium box follows the Hoetjer-Berge-Fuji emission equation. Subsequently it is possible to calculate the emission of mercury at different ventilation rates and make an interpretation for the needed ventilation rate keeping the mercury concentration below the threshold limit value.

\section{Further research suggestion}

Based on our findings and literature reading, we hypothesised that mercuric chloride treatment may also cause deterioration of the collection. This deterioration can be already observed by the naked eye, i.e., discoloration and fluorescent effect of the paper substrate. Therefore we recommend further research on the occurring mechanism of cellulose degradation by mercuric chloride.

\section{Authors' contributions}

$\mathrm{J}$ supervised the experimental field and lab studies, performed the calculations and drafted the manuscript. RD described the mercury problem, cosupervised the field studies, delivered the original materials for lab-studies and helped to draft the manuscript. RS had a serious part in the discussion on the feasible possibilities for mercury reduction and helped to draft the manuscript. All authors read and approved the final manuscript.

\section{Author details}

${ }^{1}$ TNO Applied Environmental Chemistry, Utrecht, The Netherlands. ${ }^{2}$ Naturalis Biodiversity Center, Leiden, The Netherlands. ${ }^{3}$ Coldenhoven Papier, Eerbeek, The Netherlands.

\section{Acknowledgements}

The TNO co-financing program, Naturalis Biodiversity Center and Coldenhove Papier, the Netherlands are highly acknowledged for funding our work. Eric Cornelissen, Willie Heyman and Alex van Renesse van Duivenbode are highly acknowledged for the analysis.

\section{Competing interests}

The authors declare that they have no competing interests.

Received: 18 June 2015 Accepted: 4 December 2015

Published online: 16 December 2015

\section{References}

1. Theakston F, editor. Air quality guidelines for Europe. 2nd ed. Copenhagen: World Health Organization Regional Office for Europe; 2000.

2. Mercury and health. http://www.who.int/mediacentre/factsheets/fs361/ en/.

3. Anonymous. Development of $\mathrm{WHO}$ guidelines for indoor air quality. Report. Copenhagen: World Health Organization; 2006. p. 27.

4. Dusseldorp A. Health-based guideline values for the indoor environment. Report 609021044/2007. Bilthoven: RIVM; 2007. p. 97

5. Briggs D, Sell PD, Block M, I'ons RD. Mercury vapour: a health hazard in herbaria. N Phytol. 1983;94:453-7.

6. van Steenis CGGJ. Verslag van de Hoogleraar-Directeur over het jaar 1984. Report. Leiden: Rijksherbarium; 1984. p. 58.

7. Purewal $V$. The identification of FourPersistent and hadardous residues present on historic plant collections housed within the national museum and galleries of wales. Collect Forum. 2001;16:77-86.

8. Havermans JBGA, Cornelissen HJM, van Renesse van Duivenbode JAD, Hacquebord A. Binnenluchtkwaliteit in de depotruimten van het Nationaal herbarium Nederland—vestiging Universiteit Leiden in het Van Steenisgebouw. Report. Deflt: TNO Bouw en Ondergrond; 2010. p. 25.

9. Kataeva M, Panichev N, van Wyk AE. Monitoring mercury in two South African herbaria. Sci Total Environ. 2009;407:1211-7.

10. Oyarzun R, Higueras P, Esbrí JM, Pizarro J. Mercury in air and plant specimens in herbaria: a pilot study at the MAF herbarium in Madrid (Spain). Sci Total Environ. 2007;387:346-52.

11. Webber WB, Ernest $L$, Vangapandu S. Mercury exposures in university herbarium collections. J Chem Health Saf. 2011;18:9-12.

12. Weast RC, Astle MJ, Beyer WH, editors. CRC handbook of chemistry and physics: a ready-reference book of chemical and physical data. Boca Raton: Fla; 1986 
13. Fengel D, Wegener G. WOOD, chemistry, ultrastructure and reactions. 1st ed. Berlin: Walter de Gruyter; 1989.

14. Havermans JBGA. Environmental influences on the deterioration of paper. Delft: Barjesteh, Meeuwes \& Co.; 1995.

15. Purewall V, Colston B, Roerhs $S$. The identification of historic pesticide and fungicide residues present on herbarium material housed within the National Museum Wales. In: 11th International Conference on Particleinduced X-Ray Emission and its Analytical Applications, PIXE2007; May 25-29, 2007; Puebla, Mexico. González Offset, S.A., Ecatepec, Mexico 2007.

16. CR213. Particleboards - determination of formaldehyde emission under specified conditions. CEN Report CR 213. Report: CEN; 1984.

17. ECA (2). Formaldehyde emissions from wood based materials: quideline for the establishment of steady state concentrations in test chambers. ECA Report no. 10. Report. Luxembourg: Office for Official Publications of the European Communities; 1991.

18. ECA (10). Effect of Indoor Air pollution on hunman health. ECA Report no. 10. Report. Luxembourg: Office for Official Publications of the European Communities; 1991.

19. ECA (18). European collaborative action "Indoor Air Quality and Its Impact on Man" Evaluation of VOC emissions from building products. ECA Report No. 18. Report ISBN 92-828-0384-8. Luxembourg: Office for Official Publications of the European Communities; 1997.

20. ECA (24). Harmonisation of indoor material emissions labelling systems in the EU. Inventory of existing schemes. ECA Report No. 24. Report
ISBN 92-79-01043-3. Luxembourg: Office for Official Publications of the European Communities; 2005.

21. Hoetjer JJ, Koerts F. A model for formaldehdye release from particleboard. In: ACS Symposium Series 316; Washington DC. American Chemical Society; 1986, p. 125-144.

22. Marutzky R. Investigations on comparability of large chamber test for formaldehyde emission from wood based panels. Report CEC PRS/89/7730/ IN/22-1. Braunschweig: WKI; 1992. p. 55.

23. Havermans JBGA. Performance of the formaldehyde emission method CEN CR-213(1984). In: Roffael E, editor. Braunsweiger Workshop 1988 "Formaldehydmessmethoden"; Braunschweig, Germany. WKI; 1988.

24. Yu CWF, Crump DR. Testing for formaldehyde emission from wood based products - a review. Indoor Built Environ. 1999;8:280-6.

25. Mercury Vapor Detector Model VM 3000. http://www.mercury-instrumentsusa.com/VM3000.htm.

26. Kolar J, Strlič M, Lojewski T, Havermans J, Steemers T, Bruin Gd, Knight B, Palm J, Hanus J, Perminova O, et al. Papertreat project-preserving our paper-based collections. In: Strlič M, Kolar J, editors. Durability of paper and writing 2; July 5-7, 2008; Ljubljana, Slovenia. Narodna in univerzitetna knjižnica; 2008.

27. Boerstra A, Gelderblom A, Hegger C, Jochems D, Kerkhoff R, Odink J, Peeters E, Slob R, Strien RV, editors. Handboek Binnenmilieu 2007. Rotterdam: RIVM; 2007.

\section{Publish with ChemistryCentral and every scientist can read your work free of charge \\ "Open access provides opportunities to our colleagues in other parts of the globe, by allowing anyone to view the content free of charge." \\ W. Jeffery Hurst, The Hershey Company.}

- available free of charge to the entire scientific community

- peer reviewed and published immediately upon acceptance

- cited in PubMed and archived on PubMed Central

- yours - you keep the copyright

Submit your manuscript here:

http://www.chemistrycentral.com/manuscript/
Chemistry Central 